Please do not remove this page

RMIT

UNIVERSITY

\title{
Designing for construction workers' occupational health and safety: A case study of socio-material complexity
}

Lingard, Helen; Cooke, Tracy; Blismas, Nick

https://researchrepository.rmit.edu.au/esploro/outputs/9921858710001341/filesAndLinks?institution=61RMIT_INST\&index=null

Lingard, H., Cooke, T., \& Blismas, N. (2012). Designing for construction workers' occupational health and safety: A case study of socio-material complexity. Construction Management and Economics, 30(5), 367-382. https://doi.org/10.1080/01446193.2012.667569

Document Version: Accepted Manuscript

Published Version: https://doi.org/10.1080/01446193.2012.667569

Repository homepage: https://researchrepository.rmit.edu.au

(C) 2012 Taylor and Francis

Downloaded On 2023/04/27 00:05:47 +1000

Please do not remove this page 
Thank you for downloading this document from the RMIT Research Repository.

The RMIT Research Repository is an open access database showcasing the research outputs of RMIT University researchers.

RMIT Research Repository: http://researchbank.rmit.edu.au/

\section{Citation:}

Lingard, $\mathrm{H}$, Cooke, T and Blismas, N 2012, 'Designing for construction workers' occupational health and safety: A case study of socio-material complexity', Construction Management and Economics, vol. 30, no. 5, pp. 367-382

See this record in the RMIT Research Repository at:

http://researchbank.rmit.edu.au/view/rmit:16667

Version: Accepted Manuscript

Copyright Statement: (c) 2012 Taylor and Francis

Link to Published Version:

http://dx.doi.org/10.1080/01446193.2012.667569 


\title{
Designing for construction workers' occupational health and safety: A case study of socio- material complexity
}

\begin{abstract}
Drawing upon an empirical analysis of the design and construction of a food processing facility, a theoretical understanding of the impact of design decision-making on the occupational health and safety (OHS) of construction workers is developed. It is argued that current policy and legislative approaches to Construction Hazard Prevention through Design (CHPtD) are inherently limited because they do not adequately reflect the socio-material complexity of decision-making in construction design. Specifically, the simplistic attribution of responsibility to a single sociotechnical actor, 'the designer', does not reflect the multiple and disparate influences that impact upon OHS outcomes. Nor do existing CHPtD policy frameworks, management processes and tools, recognise the manner in which the interactions and associations between relevant project stakeholders and various non-human artefacts shape (and are also influenced by) the evolution of design decisions. Drawing on actor-network theory (ANT) and using embedded units within a case study approach, the interactions between human actors and non-human artefacts is explored in relation to the design of four components of the food processing facility. The way in which design decisions unfolded and shaped OHS experiences during the construction stage of the project is revealed. The research highlights limitations inherent in current approaches to the management of CHPtD and the need to develop a more robust theoretically-based approach to integrating OHS considerations into construction design practice.
\end{abstract}

\section{Keywords \\ Occupational health and safety, Construction Hazard Prevention through Design, actor-network theory}

\section{Introduction}

\section{Aim}

The aim of this paper is to examine the interactions between relevant project stakeholders and material objects or technologies that shape design decision-making in the construction industry, as emergent decisions about design can affect the occupational health and safety (OHS) of construction workers.

In recent years there has been a widespread acceptance of the notion that construction design professionals should bear some responsibility for the OHS of construction workers, a concept sometimes referred to as Construction Hazard Prevention through Design (CHPtD) (Gambatese and Hinze, 1997; Gambatese et al. 2005). The literature on CHPtD has focused upon providing evidence of the link between design and OHS outcomes and identifying tools and technologies that support CHPtD. However, researchers suggest current CHPtD policy fails to reflect the heterogeneity of design work in the construction industry (Lingard et. al., 2007) and identify a 'disconnect' between the CHPtD policy position and industry practice (Weinstein et al, 2005).

The research utilised an actor-network theory (ANT) approach to reveal the way in which varied professional contributors to design interact with material technologies and artefacts to create uncertain outcomes and effects. By revealing the emergent connections between social and technical determinants of design decision-making (and OHS) the research sought to explain the gap that exists between theoretical propositions about the allocation of professional responsibility for $\mathrm{CHPtD}$ and 'on the ground' design practice within projects.

Specifically, the research sought:

(1) to describe and analyse how design OHS outcomes are actively influenced and shaped by the interactions between multiple project stakeholders and non-human technological and material artefacts;

(2) to critically consider the implications of these interactions for industry policy and the management of CHPtD; and

(3) To commence the development of a new theoretical understanding of the challenges inherent in implementing the CHPtD concept. 
We first provide a critical review of the CHPtD literature and a discussion of the inherent complexity of construction design work. We then explore the implications of this complexity for the practical implementation of CHPtD before providing a general introduction to Actor Network Theory (ANT). We describe our research methods before presenting four vignettes, describing the way in which design decisions unfolded at a case study construction project. Lastly, the results are discussed and the implications for CHPtD policy and research are considered.

\section{Construction Hazard Prevention through Design (CHPtD)}

CHPtD is defined as 'the consideration of construction site safety in the design of a project'. It includes 'modifications to the permanent features of the construction project in such a way that construction site safety is considered; attention during the preparation of plans and specifications for construction in such a way that construction site safety is considered; the utilization of specific design for construction safety suggestions; and the communication of risks regarding the design in relation to the site and the work to be performed' (Behm, 2005, p. 590). CHPtD has been incorporated into OHS legislation in several industrialised countries. In Australia, a number of states and territories have incorporated CHPtD requirements into their principal OHS Acts, although requirements are not nationally consistent (Cooke et al. 2009). Notwithstanding this, a current national harmonization effort could see the adoption of the Safe Work Act 2009 (Model Safe Work Provisions)' in all Australian jurisdictions in 2012. This 'Model Act' contains clear and explicit CHPtD responsibilities.

\section{Previous CHPtD literature}

Much of the CHPtD research has focused on substantiating a link between the design of a building/structure and the OHS of construction workers (see, for example, Gibb et al. 2004; Behm 2005; Gambatese et al. 2008; Driscoll; 2005; Smallwood 1996). Although this empirical research suggests that the permanent design of a building/structure can impact upon construction workers' OHS, it remains difficult to unequivocally determine the strength or importance of causal relationships. Critics of the CHPtD concept identify a failure distinguish between the different 'design' activities involved in the building industry, confusing design of the building/structure for its intended end use with design of the site layout, the process of construction and/or items of plant/equipment being used or installed (AIA, 2008).

Other researchers have documented specific design solutions that eliminate an on-site OHS hazard or reduce OHS risk during construction (see, for example, Gibb et al. 2007; Wright et al., 2003). Some of the CHPtD solutions identified in this literature relate to the design of the construction process, rather than the permanent building/structure. Off-site manufacture of building components has been proposed as a useful CHPtD strategy (Toole and Gambatese, 2008). Given this assertion, a robust comparative analysis of the OHS performance of different building technologies is warranted to measure and compare the 'whole of life' OHS performance of off-site solutions relative to traditional construction processes.

Researchers have also identified tools that could aid the implementation of CHPtD within organizations. Examples include: (i) the development and use of knowledge-based decision support tools to provide designers with 'expert' OHS knowledge when reviewing their designs (Davison, 2003; Cooke et al., 2008); (ii) the use of visualisation tools to identify OHS hazards associated with the design of building components and the process of construction (Hadikusumo and Rowlinson, 2004); and (iii) the use of multi-dimensional Building Information Modelling (BIM) tools, to incorporate OHS considerations into construction design and planning (Toole and Gambatese 2008; Sulankivi et al. 2010; Kamardeen, 2010).

Thus far the adoption of these tools by industry has been limited. The knowledge-based tools described by Davison and Cooke et al. did not progress beyond the prototype stages of development, while the implementation of a building model capable of being used throughout the design, construction and operation stages of a building's life cycle has mainly been applied on trial 
projects, often driven by large public sector clients (Howard and Björk, 2008). Lee and Sexton (2007) identify attitudinal barriers to the adoption of BIM, including perceptions that the technology is too 'embryonic,' requires too much investment and is too far removed from existing organizational and business processes (Lee and Sexton, 2007). The limited application of information communication technology (ICT) tools raises questions about their level of practical usefulness to support CHPtD in the context of construction design work.

Harty (2008) argues that it is necessary to understand the context in which innovations are introduced in detail in order to appreciate why some innovations are adopted while others are not. Researchers have tended to develop prototype CHPtD tools and advocate their use, without attempting to evaluate how (indeed if) these tools 'fit' within professional design practice in the construction industry. It is important that the development of CHPtD tools is informed by a robust understanding of design practice within the construction industry.

\section{Complexity and construction design}

Baccarini (1996) defines complexity as 'consisting of many varied inter-related parts, operationalised in terms of high levels of differentiation and interdependency' (p.202). Project complexity can be organizational (i.e., a significant division of tasks, multiple organizational units and/or hierarchical levels, multiple specialisations and many interdependencies between organizational elements) or technological (i.e., multiple diverse inputs, outputs, tasks or specialities and many interdependencies between technologies, tasks or inputs). Design work is characterised by high levels of both organizational and technological complexity. Construction design teams are 'temporary, multidisciplinary and network-based organizations' (den Otter and Emmitt, 2008, p122) and design involves a network of tasks, requiring contributions from many specialists and the involvement of a complicated 'web' of inter-organizational relationships (Pietroforte 1995; 1997; Nicolini et al. 2001).

Interdependency between design tasks requires frequent and detailed interaction between contributors to ensure that components are compatible (Gray et al. 1994). The complexity inherent in construction design is highlighted in research by Austin et al. (1999) who report that the design of a typical building comprised between seven and ten iterative loops. Each of these iterative loops involved between five and 30 interrelated loops. The number of design tasks was around 350-400, and the number of information dependencies was over 2400. Austin et al. (2001) found similar complexity in the conceptual design of a single building element (a relatively simple modular window system).

The assumption that design decisions are made exclusively by occupants of an abstract sociotechnical role, 'the designer' is problematic. In construction it is often suppliers and subcontractors that demonstrate innovation and independent decision-making in the design and manufacture of specialised building components (Gray and Flanagan 1989; Slaughter 1993). In the context of increased product complexity, specialist contractors are often responsible for the detailed design of specific building elements (Haviland 1996). This is acknowledged by Wright et al. (2003), who concede that many technology-based CHPtD solutions are driven by building systems manufacturers and not by principal design consultants.

\section{Implications for CHPtD research}

CHPtD research has attempted to superimpose a standard OHS risk management process on the activity of design, leading to the development of protocols for the identification of hazards, the assessment of risk, and selection of appropriate risk controls prior to specific 'hold points' in the development of a design (see, for example, a description of this process provided in Lingard and Rowlinson, 2005). The assumption underpinning standard OHS risk management activities is that hazards (defined as conditions that have the potential to cause harm) can all be clearly identified at the beginning of the linear process of risk management. Any hazards that are not identified at this step will be excluded from the subsequent analysis of OHS risk (i.e. an assessment of the likelihood 
that harm will eventuate and the consequence of that harm). Thus, OHS risk management processes lack the flexibility to cope with emergent hazards.

Another difficulty with standard risk management methods is that they are based upon the assumption that a project can be decomposed into its constituent parts enabling risks inherent in each of those parts to be controlled. Although embodied in widely accepted methods for managing project scope (i.e., work breakdown structures and milestone plans), project time performance (i.e, project networks and project evaluation and review techniques) and project costs (i.e, cost breakdown structures and earned value analysis), Cooke-Davies et al. (2007) argue that decomposition models are not well suited to the analysis of complex, nonlinear, dynamic systems, like construction projects. Pavard and Dugdale (2006) suggest that complex systems have a limited functional decomposability. In the case of design work in construction it is difficult (if not impossible) to decompose system elements into design functions, professional contributions or logical 'steps' because they are in permanent interaction with one another and facets of the external environment. This interaction creates emergent properties that cannot be identified or anticipated even with a good understanding of individual component parts.

A growing number of project management scholars call for the use of methods that are more holistic and qualitative in the analysis of project processes (see, for example, Williams 1999). In this context, a case can be made for CHPtD research to explore more sophisticated explanatory models of the way in which design decisions with the potential to influence construction workers' OHS are made. Such models are important in order to develop CHPtD interventions that are based upon a closer connection between industry practice and theory.

\section{Actor-Network Theory}

Actor-network theory (ANT) is a useful approach through which to investigate the aetiology of design decisions with the potential to influence OHS in construction. ANT is an ontological framework for the investigation of socio-technical interactions. One of the key features of ANT is the notion of 'symmetry' in which neither a social nor a technical position is privileged.

'Transformation' is understood to occur through dynamic network effects resulting from the formation and reconstitution of relations between human actors and non-human artefacts, a process termed 'heterogeneous engineering' (Law, 1992). ANT studies do not view events as attributable to an external social force impelling a group of actors to behave in a certain way. Rather, connections between human actors and non-human actants are understood to effect transformation. Latour (2005) states that ANT studies regard the social as something that needs to be explained, rather than a force that provides an explanation for events. ANT is also sometimes referred to as the 'sociology of translation' because it concerns itself with the way in which relations between human and nonhuman entities induce transformation by triggering chains of unexpected but traceable changeinducing events (Latour, 2005, p.106). ANT acknowledges that the connection between decisions, actions and outcomes is complex and uncertain. ANT studies have also been characterised by a reversal in causality in which technological artefacts are not regarded as passive objects, whose existence is merely enabled by human actors. In ANT thinking, it is possible for technologies to become active agents with the ability to shape and sometimes undermine decisions made by human actors.

The primary focus of ANT is to examine the dynamic process of association, change and reconstitution between actors and actants in a network (Latour, 2005). Consequently, ANT lends itself to the analysis of decision-making and practices in construction projects in which project teams comprise heterogeneous, self-organizing coalitions of autonomous agents between whom associations vary over time (Fernandez-Solis, 2008). Further, ANT does not establish the boundaries of networks a priori and networks are therefore not restricted by project, organizational or industry boundaries (Latour, 2005). In this, ANT is well-suited to the analysis of the OHS implications of design decisions, as it is has been shown that OHS is influenced by factors originating outside the boundaries of a project (HSE, 2003). 


\section{Previous ANT research in construction}

An ANT approach has been used to analyse a number of construction project phenomena (see, for example, Harty, 2008; Schweber and Harty, 2010; Sage et al., 2010, Tryggestad, 2009). In particular, ANT has been deployed is to expose the complex interactions between project stakeholders and material artefacts inherent in the design of buildings (see, for example, Ewenstein and Whyte, 2007). Tryggestad et al. (2010) used ANT to reveal how construction design work is a collective activity characterised by distributed knowledge production. The resulting process is reflexive, flexible and characterised by serendipitous 'trade-offs.' Harty (2010) also used ANT to describe the way in which the use of a new technology is 'translated' through unfolding relations between the technology itself and various human entities, including user groups. CHPtD can be regarded as a social technology, similar to ecologically sustainable construction, and we suggest that its adoption can be usefully analysed using ANT.

\section{ANT concepts}

Two key ANT concepts drawn upon in the present analysis are intermediaries and mediators. The former is defined by Latour (2005) as an entity that "transports meaning or force without transformation" (p.39). An intermediary is a passive component of an actor-network that does not transform action and is sometimes referred to as a "black box" because its outputs can be defined with knowledge of its inputs. Latour also comments that intermediaries can be regarded as a single entity even when they are made of many component parts because they are predictable, known and stable, although sometimes for a limited period only. In contrast, mediators are active entities within an actor-network. They "transform, translate, distort and modify the meaning of elements they are supposed to carry” (Latour, 2005, p.39) and, as such, the outputs of a mediator cannot be predicted from knowledge of its inputs. One of the fundamental purposes of ANT studies is to identify when and how actors act, i.e., when they are behaving as intermediaries and when they are behaving as mediators. Further, it is possible for an intermediary to become a mediator as Latour describes the properly functioning computer (a black-boxed intermediary) changing into a complex mediator when it breaks down and produces outputs that are no longer predictable.

The research gap

$\mathrm{CHPtD}$ researchers have not yet undertaken a robust analysis of the way in which dynamic associations (between multiple project participants and material artefacts) unfold to produce a level of OHS. This research sought to address this gap by adopting an ANT approach to the analysis of socio-material complexity inherent in the implementation of CHPtD. In particular the research explored the role of human actors and material artefacts in actor networks engaged in construction design. In particular, the research sought to identify the roles of intermediaries and mediators in these networks, as well as instances in which passive intermediaries became active moderators which ultimately shaped design and CHPtD outcomes.

\section{Research setting and methods}

\section{The project setting (Case Context)}

The research adopted a case study approach, favoured for the rich causal data that it produces (Orum et al, 1991; Eisenhardt, 1989; Fellows and Liu, 1997; Yin, 1994). This was considered paramount to the research, due to the lack of deep theoretical understanding of the intricacy of designing for OHS in construction. Substantive evidence of the reasons why design decisions were made and how they influenced OHS outcomes on site were collected and 'chains of evidence' constructed within the context of the case. The case comprised four embedded units, each a particular building element of the project case.

Data were collected at a food processing plant located in the outer suburbs of Melbourne, Australia. The plant had been partially destroyed by a fire in January 2010, resulting in closure and the loss of 1,700 jobs in the local area. Originally the client decided that the plant would not be rebuilt. It had 
been in operation since 1919 and, despite many upgrades and extensions, the plant was of an old design and the client organization had newer, more efficient sites in other locations. However, to prevent the loss of employment in the area, the State Government of Victoria offered substantial monetary assistance to the client to support re-construction and fast-tracked the planning process to facilitate this. As a consequence of this support, the client decided to re-build the plant and appointed a contractor under a 'design and build' contract to undertake the project. The client also engaged specialist designers for the water treatment plant and elements of the processing equipment to be installed in the facility. To combat the risk of losing business to competitors during the reconstruction period, the client set an ambitious date for the re-opening of the plant, compressing the design and construction work into a ten month period.

\section{The legislative context}

At the time of the data collection there was no statutory requirement under the Victorian OHS legislation for designers to eliminate or reduce OHS risk to construction personnel. Section 28 of the Victorian Occupational Health and Safety Act (2004) requires the designer of building or structure to be used as a workplace to ensure that it is designed to be safe and without risks to the health of persons using it as a workplace. WorkSafe Victoria, the regulatory agency, has published guidance material stating that the design of the construction and demolition phases of a building or structure's lifecycle do not fall within the scope of Section 28 (WorkSafe Victoria, 2005). As a consequence, in the state of Victoria it has been common practice for design teams to assess and attempt to design out OHS risks relating to the operation stage of a facility but not consider the health and safety of construction workers in the same risk management process.

\section{Data collection}

Gorse and Emmitt (2007) identify the need to investigate social interaction and communication in 'live' construction projects. In-keeping with this recommendation, the data collection approach adopted involved a number of different methods including: (i) direct observation of project team interactions; (ii) interviews with project actors; and (iii) inspection of artefacts, such as aspects of the physical worksite and project documentation. Gluch (2009) describes the observation of situated social interaction using an ethnographic approach as particularly useful because people are not always aware of the knowledge they bring to a situation and sometimes may not even have the vocabulary to talk about it. This may be particularly true in the case of CHPtD which is a relatively new concept in the Australian construction industry and about which most design professionals have received little instruction during their professional education and training. Also, the ability to observe and record activities as they occur is a valuable tool in the study of human activity in which there may be a difference between ideal and manifest behaviour. For example, Larsson (2007) reports that when asked to describe their behaviour, people tend to give an account closer to the ideal than the manifest.

The principal features of interest for data collection were traceable associations between actors and actants, which resulted in the transformation of design with the potential to influence CHPtD. The researcher attended fortnightly design team meetings at the project site between $27^{\text {th }}$ May 2010 and $13^{\text {th }}$ October 2010, and weekly meetings thereafter until $15^{\text {th }}$ December 2010 . Direct observation of project participants was followed by a series of interviews to explore the meaning that participants attributed to design decision-making. Proponents of ANT suggest researchers "follow the actors" (Callon 1991) and allow them to define the boundaries of the research. This approach was followed in the identification of actors for interview. In particular, the researcher identified a number of building elements for analysis, based on observations of design team meetings. For each element, the design and build contractor's project manager was interviewed along with the design professions with contractual responsibility for the design of the specific element. From these interviews, other entitles whose physical properties, actions or interests shaped the design became apparent and these 'leads' were followed up with further interviews. This process continued until no new leads were identified in actors’ interviews. 
In total 18 project participants were interviewed, including some 'external stakeholders.' Interviews were conducted with, representatives of the 'design and build' contractor, the structural engineer, the hydraulic engineer, the project architects, the structural steel subcontractor, the plumbing subcontractor, the concrete subcontractor, the services installation contractor, the Environmental Protection Authority (EPA), the local water authority, the Country Fire Authority (CFA), the specialist fire engineer, the building surveyor, the trade waste design consultant and the client. The interviews explored project stakeholders' expectations, motivation and reasoning relevant to design decisions pertinent to four design aspects selected for analysis. These embedded units are presented as 'vignettes' below. The vignettes provide a description of the way in which decision-making was constituted through interactions between the various project stakeholders and non-human artefacts. The manner in which the interactions between human actors and non-human actants shaped CHPtD is revealed in each vignette.

\section{Design issues with relevance to construction workers' OHS}

\section{Design issue one - fire damaged columns}

As a result of the insurance company's assessment of the fire damage, three columns and the roof structure of the evisceration building were extensively damaged and were to be replaced. However, the remainder of the building was deemed to be structurally sound. From the beginning of the project, tensions regarding the optimal structural support solution for the evisceration building were evident.

From the outset, the construction contractor responsible for the building design and construction expressed a preference that the entire building be demolished and re-constructed. The project manager commented "...we tried early on to persuade the client to pretty much ball the whole area over...but anyway that was our brief." The client was driven by a concerns about being able to deliver on a production contract with a large customer (a leading supermarket chain) and preferred to retain as much of the building as possible, believing this to be the quickest re-construction option. At this point in the design it was assumed that the columns that had not been fire damaged were in good condition and the columns were behaving as passive intermediaries in the translation of the design.

However, the behaviour of the columns altered dramatically when, during stripping back, extensive damage to the blockwork encasing the columns was revealed and it became apparent that a number of the columns were significantly affected by rust. At this point the columns became active mediators in the actor-network. The condition of the columns themselves became a significant influence in the design of the structural support system. Again, the contractor suggested the columns be demolished, but the client's instruction was to continue with the repair work. The contractor's project manager accepted this instruction but continued to believe this to be the least efficient design solution, commenting with resignation that 'so from that point we had to move on to the repair.'

Having made the decision to retain as much of the original structure as possible, the design goal for the evisceration building was further changed when a decision was made to increase the facility's production capacity. This decision was taken by the client who decided to reap the maximum benefit from the subsidy awarded by the State Government of Victoria. However, increasing the facility's capacity changed the production plant and building services requirements for the evisceration building, significantly increasing the load requirements for the columns. Thus, the upgraded machinery and equipment, acted as a significant mediators, creating new challenges for the structural design consultant. The engineer advised the client that the new design requirements would require retained columns to be substantially repaired and strengthened, again suggesting that replacing the columns may be a more efficient solution. The engineer commented that "the client made the decision that it was more economical to retain the existing columns and strengthen them." 
The column strengthening was to be achieved using a system of stiffening plates, in addition to removing and replacing those sections of the columns that could not be repaired. The strengthening involved the installation of a new column section behind the existing column. The length of the new sections varied depending upon the degree of dilapidation. Consequently, it was decided that prefabrication was not an appropriate method. A constructability review (undertaken with the subcontractor who would perform the work) revealed that the main OHS risk inherent in the strengthening was the risk of working at height. To mitigate this risk it was decided that work would be undertaken using a mobile elevated work platform (a 'cherrypicker'). This decision was documented in a work method statement. This paper output of the constructability review defined work practices for the column strengthening and, from that point, construction methods were not modified by actors involved in the column design or by further changes to the design itself.

The requirement to install props to support the structure while the strengthening work was underway presented a problem for the use of a 'cherrypicker' and also impacted upon other subcontractors working within the building area. Further translation of the design took place as a result of interaction between the construction methods, i.e., use of the 'cherrypicker,' the structural engineer and column erection subcontractor. Following consultation with the subcontractor, the design was modified to remove the requirement for propping the columns during construction. The engineer developed a safe method by which this could be achieved. He stated "From our perspective, we are worried about the structural integrity of the building... so, for example, some of the stiffening elements would be need to be taken out so we would say [to the subcontractor] you need to put some elements in before you take some elements out."

Engaging the relevant actors in the constructability review for the column design was beneficial as it transformed the design process from one in which the OHS of construction workers may have been compromised, to one in which CHPtD was integrated. The subcontractor commented "on other jobs they just give you stuff and you end up having to deal with it."

However, there remained poor alignment of actors' interests in relation to the evisceration building column design. Latour (1987) used the term 'trial of strength' to describe a lack of alignment which can alter the constitution of an actor-network as poorly aligned actors may cease to interact.

The decision to retain as much of the existing structure as possible precluded the use of alternative designs which would arguably have been safer. For example, the pre-fabrication of columns would have dramatically reduced the need to work at height. Ironically, given the client's concerns with construction time, the 'design and build' contractor commented that "....it took us longer to fix it than it would to build a new one".

\section{Design issue two - waste discharge system}

In order to maximise the benefit derived from the government subsidy, the client opted to reconstruct the waste discharge system at the plant. The underground waste treatment system had not been badly damaged by the fire, however the existing system did not separate trade waste, human waste and stormwater and no longer met the requirements of current environmental legislation. The client's decision to substantially increase the production capacity of the new plant necessitated a major upgrade of the waste discharge system and a specialist hydraulic engineer was engaged by the client to design the new system.

The design of the waste discharge system evolved as decision-makers interacted with one another and with physical features of the system. From the outset, the local water authority was an important actor in the network, expressing concern that discharges from the plant would exceed capacity and flood the authority's local water treatment infrastructure. 
The originally proposed design separated the various discharge streams such that trade waste, sewerage and stormwater would each be pumped via dedicated lines. Sewerage and trade waste were pumped to a dedicated pumping station belonging to the water authority but located on the client's premises. However, the physical properties of the waste itself mediated the water authority's concerns and ultimately shaped the design requirements for the waste discharge system. The water authority advised that to accommodate the waste flow rates associated with the increased production capacity of the new plant, the pumping station would also need to be upgraded at the client's expense. This was deemed financially infeasible by the client and a new design solution was sought.

The hydraulic engineer proposed some alternative design solutions to the water authority and preliminary approval was obtained so that site preparation work could commence. However, the detailed design of the waste discharge system was undecided. After considerable exchange of information and meetings between the hydraulic engineer and the water authority, a spreadsheet of design options was drawn up by the water authority. The spreadsheet provided the basis upon which the stakeholders were able to articulate their different interests and become actively involved in the negotiation to find an appropriate solution to the problem. Following multiple interactions via emails, telephone conversations and in face to face formal and informal meetings, a workshop was convened at which the actors' representatives were able to argue their positions. At this workshop a design solution was finally agreed and accepted by all parties.

The agreed design incorporated septic tanks with a two hour retention system. The hydraulic engineer described the role played by the workshop in enabling the convergence of stakeholders' interests and stabilisation of the design as follows: "We were then able to thrash out a suitable concept. After that meeting we really had the concept that is out there now....We walked away from a workshop session with one of those options refined, in-keeping with what everyone around the table thought was an agreeable solution."

The initial design of the septic tank utilised large concrete pipes which would be lowered into a pit using a crane. Workers would then enter the pit to seal the joints and ends of the pipes, presenting OHS risks associated with working inside a confined space. However, during the design it became apparent that prefabricated "off the shelf” fibre-glass septic tanks could also be utilised. The prefabricated fibre-glass option was determined to be cost-effective and easier to install. Minor alterations required to make the pre-fabricated tanks fit for purpose could be performed at ground level prior to installation. However, the fibreglass tanks were not designed to take live loads so bollards were used to demarcate the perimeter of both the septic tanks and the holding tank to prevent damage or collapse by truck movement on the site. In the original design, the septic tank was located next to the existing pumping station, which was situated within 10 metres of an old filtration pond. While the original design sited the tank some distance from the existing filtration pond, the water authority required the new holding tanks to be located between the pumping station and the pond to reduce the number of turns in the pipes carrying waste material. This presented an OHS issue during construction as water constantly flowed into the excavation and had to be pumped out.

The decision of the client to retain and utilise as much of the existing drainage structure as possible increased the complexity inherent in the design and construction of the waste discharge system, as the condition and location of the existing pipes became a major shaping factor. The design required that any new lines installed were to connect with the existing drainage pipes. However, very limited information about the existing drainage system was available to the design and construction team requiring extensive exploratory work. The 'design and build' contractor's project manager commented: "In a perfect world, if we had time we would do a full video inspection and go through it with them and say this is going to be a problem or we cannot do it ...[but] in this case we have just said that we would make do with what we have got, and roll on." In a number of instances the existing drainage system had to be exposed to determine suitability of reuse. This resulted in 
plumbers having to dig through existing concrete and 'work around' other services located in the same area as the waste pipes. Uncertainty about the location, depth and nature of underground services increased the OHS risk to workers engaged in this work.

\section{Design issue three - services and equipment in the boning and packing building}

The original boning and packing building was completely destroyed in the fire and had to be rebuilt as part of the new facility. The design of the ceiling space above the boning and packing building was shaped by an actor network that extended beyond those directly involved in the project itself to include food safety authorities, a large supermarket chain as well as specific elements of the building planning process.

The ceiling space was designed to house plant and equipment necessary for production and an external regulator (The Australian Quarantine and Inspection Service) established some specific requirements in relation to the health and safety aspects of food processing and handling. For example, the boning and packing area was to be maintained at a temperature of between five and $10^{\circ} \mathrm{C}$ during production. This required the installation of large refrigerator units measuring three by four metres in the roof space. Consequently, the layout of the roof space was based on the mechanical design and location of these units.

Additionally, all the plant and equipment located in the boning and packing area would be serviced by utilities located in the roof space, requiring that all the services feeding the equipment, air, water, electricity, etc. would run through the roof space. Secondary steel was incorporated in the design to support the plant, equipment and services that were to be located in the roof space. The plant and equipment itself was therefore an important mediator, actively shaping the design of the boning and packing building.

However, a great deal of uncertainty surrounded the specifications for plant and equipment for installation in the boning and packing room, which was crucial to the ceiling space design. When construction commenced, the client's plant and equipment requirements for the boning and packing building were not known. At this time, the 'design and build' contractor's project manager advised the client that, to ensure the adequacy of the supporting structure to meet the plant's operational needs, equipment requirements were needed urgently. He commented "We told the client that if they couldn't lock their equipment positions down within six weeks, we weren't confident that we could provide them with adequate steel work."

As the design work progressed, the plant and equipment continued to act as an important mediator in the design but uncertainty surrounding the specification of this plant and equipment remained. Indeed, the design requirements were changed through interactions with additional actors who joined the actor network. For example, a major supermarket chain changed its requirements for food packaging, resulting in changes to plant and equipment to be installed mid-way through the design. This altered requirements for the location of the supporting structure and services. To cope with the uncertainty, the mechanical design team decided to incorporate an over-engineered steel support grid for the roof space. Ongoing uncertainty concerning plant and equipment to be installed in boning and packing room played an active significant role in the shaping the design of the support grid.

The symbiotic nature of design was also evident in the case of the services and equipment in the boning and packing room as selection of plant/equipment was simultaneously influenced by and influential in the design of the building itself. The choice of plant and resulting roof space requirements for services was influenced by pre-determined height limits arising from the expedited planning approval process that had occurred at the outset of the project. According to the 'design and build' contractor's project manager "[space restrictions] were a product of the fact that when the discussions were going to push the building ahead it was agreed with the Minister of Planning, the local council, the client and ourselves, that as the planning drawings were pushed through in 
about a week, that a very quick set of drawings were done and they determined the height of the building....For us to go back and change [the nominated heights] would have put the project at risk." The immutability of the building's dimensions substantially restricted designers' options.

The interaction between the roof space design, plant size, location and the mechanical services layout had 'knock on' effects on construction workers' OHS. For example, the location of walkways in the roof space was determined by the placement of structural elements and the position of plant and services. As a result, the walkways had to be constructed over and under steel beams increasing the length of walkway to be laid and the number of joins required. Thus, workers installing the walkways had to manoeuvre components in congested areas, increasing the risk of manual handling-related injuries and the duration of exposure to working at height was increased.

The contractor noted that the concurrent design and construction of the boning and packing building had presented safety challenges: "Normally the preliminary design process is to uncover issues such as how high should your building be. We almost skipped prelim. design to a certain degree. So that has caused us issues. So for the roof height, rather than have a flat walkway they will dip under a beam. All those sorts of things that if you could have avoided it then you would have."

\section{Design issue four - fire rating the boning and packing building}

The fluidity of the plant and equipment specification also presented challenges in the design of the boning and packing building for the purposes of satisfying fire rating requirements. It was the client's preference that a sprinkler system not be installed into the building. However, after construction work had commenced, a review by a registered building surveyor revealed that, if a sprinkler system was not installed, to satisfy the Building Code of Australia (BCA) requirements, it was necessary to 'design in’ a fire-rated wall to reduce the size of the building compartments.

The necessity to include a fire wall was made once the primary structure was already erected. As the 'design and build' contractor's project manager commented: "We were literally putting up a building when we found that our areas were over what we thought they were. Whereas normally you would be in a conceptual design you would see it and stop and evaluate it, whereas having been committed to a building out there, we had to make the decision to put a block work wall in."

The original plan was to erect the fire-rated wall using a 'tilt-up' panel method of construction. However, it was understood that penetrations would need to be made in the wall to accommodate plant and services. As there remained uncertainty about the plant and equipment that was to be installed in the boning and packing building, the dimensions and location of these penetrations was not known. At this stage the plant and equipment was behaving as a mediator in the network actively shaping design decisions and material choices. Consequently, it was decided to construct the wall using block work to allow for penetrations to be more easily made when the building's equipment and services design was finalised.

The Country Fire Authority (CFA) also emerged as an important member of the actor-network as it became apparent that the building design deviated from the specification standards contained in the BCA, necessitating approval of these design aspects by the CFA. Notwithstanding the designers' decision to construct the building using fire retardant panels, the CFA advised that they would not support the original building design because the design did not provide full perimeter access for their fire appliances.

At the time of constructing the block work wall, the number, size and location of penetrations were not known. The project manager commented: “The equipment contractors were direct to [the client] and they were hard to pin down. So we always knew that product had to come through...so this issue has see-sawed back and forth with the issues that we have had with the openings." 
When the plant and equipment requirements were eventually forthcoming, the behaviour of the plant and equipment in the actor network changed from that of an active mediator to that of a passive intermediary. The properties and character of the plant and equipment became temporarily predictable and stable. However, the passive behaviour of the plant and equipment in the actor network was to be short-lived due to ongoing contention about the appropriateness of the fire rating of the boning and packing building. Once the plant and equipment specification was issues it was discovered that the required penetrations were considerably larger than the $600 \mathrm{~mm}^{2}$ allowed for in the block work wall. Not only would this necessitate re-work, but it would also compromise the fire integrity of the wall. Work commenced to enlarge the penetrations, presenting specific OHS risks to workers involved in the demolition work. Then, once the plant was installed, the installation contractor advised that the openings in the block work wall could actually have been $40 \%$ smaller in size.

To maintain the integrity of the firewall, the penetrations were then in-filled to the recalculated sizing. However, this reconstruction had to take place after the fixed plant was already in place and so workers had restricted access to the work area. The construction of the penetrations required that the block work be cut and the flashed with stainless steel to adhere to the food safety regulator's requirements. Whilst the openings were not high in the wall, scaffolding was required to provide access.

The openings in the firewall remained a subject of contention with the fire authorities and the actors in the network became engaged in a trial of strength concerning the suitability of the firewall. The CFA maintained that the block work wall could no longer act as a firewall when it included penetrations. In the CFA's opinion the building was an oversize single building that required a sprinkler system to comply with the BCA.

An assessment was commissioned from a fire engineer who advised that 'fire tunnels' would be required either side of the wall to stop the spread of fire, smoke and heat. The size (or length) of the tunnels was to be proportional to the size of the openings - the larger the opening, the longer the tunnel. However, at this point the plant and equipment began to behave as a mediator once more, actively shaping decisions about the best way to achieve the required fire rating performance for the building. Limited space was available for the construction of fire tunnels as fixed plant had already been installed either side of the fire wall. The original design for the tunnel required a 2.5 metre length, for which there was insufficient space. A reduction in the size of the openings permitted a reduction in tunnel length to 1.8 metres. The construction of the fire tunnel commenced without CFA approval, in order not to fall behind the project schedule. In the event, the CFA did not approve this design, insisting on the installation of a full sprinkler system to the boning and packing building. In order to obtain approval for the building design, the client had to agree to retro-fit the building with a sprinkler system after the start-up of production.

It was clear that alignment of actors' interests was not achieved in the translation of the boning and packing building design and there remained disagreement concerning whether the fire wall with fire tunnels should be deemed to satisfy the requirements of the BCA. The project manager expressed his frustration as follows: "It was quite difficult to explain to the CFA what the site does and how it works and therefore what the risks are and what the issues are...They don't really understand the operations of the plant in that they see a factory, they think warehouse, they think mounds and mounds of cardboard. That's the perception that I get. In a food processing environment it's mostly stainless steel and mostly non-combustible. It's like there are whole sections of the plant that are at sub zero, or zero.... If we had a lot of time on our hands, if we had had another 12 months then we might have said fine we will take our line and you take yours, because we disagree we go to building appeals. Obviously that would have been a way to resolve that, but we couldn't afford [the delays]." 
The late inclusion of a sprinkler system into the design meant that the installation presented specific OHS challenges as the workers undertaking the installation needed to negotiate existing plant and services located in the ceiling, a confined space. Another area of OHS concern was access to the underside of the ceiling to install the sprinkler heads. Fixed plant and equipment had been installed in the building, which could not be moved to provide space for access equipment. Further, the production plant was operational when the sprinkler system was installed, providing only a short window of opportunity to carry out the work.

\section{Discussion}

\section{CHPtD in actor-networks}

The four vignettes reveal how design decisions 'unfold' within actor-networks and influence construction workers' OHS in construction projects. The quality of CHPtD outcomes in each vignette was influenced by the dynamic interaction between a range of relevant project stakeholders, as well as the material artefacts that constituted participants' understanding of the viability or appropriateness of available design options for the project. Although the identity and configuration of actors differed, all of the vignettes revealed that OHS outcomes for construction workers were co-produced by a combination of social and material factors. Figure 1 provides a simplified representation of the network of actors and their interactions for the design of the wastewater system.

The vignettes reveal considerable tension between actors' interests and material agency. From the outset of the project, the design of the facility was shaped by complex interactions between multiple actors and the material condition of the damaged building. The insurance company had inspected the site the day after the fire and made an assessment of the extent of the damage which determined the size of the claim to be paid to the client organization. Consequently the project budget was determined by this assessment and the decision was made to retain as much of the original structure as was possible. This decision presented a number of design challenges in the project which had relevance for CHPtD. For example, the decision to retain the original structure of the evisceration building resulted in the need to strengthen the columns supporting the structure, presenting challenges for the manoeuvrability of equipment to gain access to height. The decision to retain as much of the original concrete pipe in the underground waste discharge system significantly shaped decisions concerning the design of the system, influencing CHPtD. The insurance company's original assessment report, the project budget and original client brief became critical artefacts in the transformation, through design and construction, of the physical condition of the facility, defining the viability of design alternatives and the selection of the construction technologies.

The vignettes also reveal that the client's goals for the project changed as the design evolved and new information was introduced by different actors. For example, uncertainty concerning the space requirements for equipment and services to be installed in the boning and packing room impeded detailed consideration of CHPtD in the design stage. The complex web of factors influencing the OHS performance of the design are perhaps best illustrated by the decision of a major supermarket chain to change packaging of meat products, which determined the design of the plant and services to be installed in a roof space already constrained by height restrictions associated with the original building planning approval. A similar level of uncertainty surrounded decisions made concerning the fire rating of the boning and packing room. The end product of a lengthy trial of strength between the suppliers of specialist plant and equipment, the project engineer, the CFA, a specialist fire engineer and the 'design and build' contractor was a decision to retrofit a sprinkler system into the building after its completion. This decision illustrates the way in which OHS hazards can emerge from the complex interaction and articulation of actors' interests and technological artefacts, even after the commissioning and handover of a facility.

These findings are consistent with the argument of Tryggestad et al. (2010) who suggest that design decisions are the output of collective action. They suggest that design goals should not be viewed as 
invariant inputs that are established at the commencement of a project and remain unchanged. Rather, design is a flexible process of engaging in 'trade-offs' to achieve workable solutions to emergent problems. This contingent view of design raises questions about the practical implementation of CHPtD because it is inconsistent with the standard approach to OHS risk management which is not sufficiently flexible to cope with adaptive decision-making and emergent hazards.

The vignettes also reveal that it is problematic to allocate responsibility for OHS in construction design in a simplistic way to an individual design professional, e.g. 'the architect' or 'the engineer.' Law (1992) cautions against 'punctualizing' actor-networks by treating parts of the network as if they were a 'black box.' Black boxing parts of an actor network renders invisible the complex socio-technical components that make up these networks. The vignettes demonstrate the importance of 'unpacking' design decision-making associated with specific building components to understand the heterogeneity of players and interests involved in decisions that influence construction workers' OHS. Our empirical results challenge the assumption that building design can be decomposed into specialist packages for which a specific design consultant is held singularly responsible. The punctualization of actor networks gives the appearance that the design of a building component is produced by a single point actor and implies that CHPtD responsibility rests with the "seemingly simple author of that action." (Law 1992, p.385). The vignettes reveal that a more nuanced view of construction design decision-making is warranted and the allocation of professional responsibility for CHPtD must be informed by a robust understanding of the complex socio-material interactions shaping design decision-making in any given project situation.

\section{The interests and influence of external stakeholders}

One particularly striking feature of all four vignettes is the significant role played by actors external to the project in shaping design decisions that subsequently influenced construction workers' experience of OHS. External stakeholders included the insurance company, the State Government of Victoria, the CFA, AQUIS, the local water authority and even the supermarket chain that purchases the client's product. Harty (2008) suggests that construction projects are 'relatively unbounded' contexts in which actor-networks are continually changing. He argues that an ANT approach is ideally suited to the analysis of phenomena in relatively unbounded contexts because it does not define, a priori, the boundaries of any particular actor-network. Thus, the analysis of an actor-network should not be restricted to members of a particular social group, such as a profession, organization or project. Our results strongly suggest that any consideration of CHPtD within construction projects should not be contained within the boundary of a single organization or project. Indeed, greater recognition of the role played by parties external to projects in shaping CHPtD outcomes is needed.

\section{Implications for CHPtD policy and practice}

The research findings have important implications for the implementation of CHPtD policy and practice. First, the importance of the role and influence of external stakeholders suggests that the implementation of CHPtD processes within a single design organization and/or construction project is likely to be of limited effectiveness. Harty (2008) argues that innovation that aims to change the way that organizations function needs to be implemented "across [the] inter-organizational landscape” in which these organizations operate (p.1030). This is very apparent in the multistakeholder construction environment.

The breadth of the actor-networks which generate design decisions with implications for construction workers' OHS also suggest that an industry-level approach to the development of CHPtD policy and practice may be needed. Given the socio-material complexity surrounding construction design, it is problematic and arguably inappropriate to ascribe responsibility for CHPtD to an abstract socio-technical role, i.e., 'the designer.' Although OHS legislation often defines the role of the designer broadly, design is still understood to be the product of an individual duty-holder's activity. Definitions of 'the designer' embodied in OHS legislation do not adequately 
reflect the fact that construction design is a distributed, heterogeneous activity characterised by collective knowledge production. As such it is difficult to identify the degree of responsibility attributable to individual actors.

It is also possible that many of the protocols, procedures and tools available to support the implementation of CHPtD are currently unable to cope with the dynamic and contingent nature of design work in the construction context. For example, advocates of BIM, assume that detailed building information models can be constructed at an early design stage and that these models can be used to undertake a comprehensive analysis of the OHS risks presented by a particular design. However, this proposed use of BIM technology assumes that highly detailed and stable information about building components is available at a particular assessment point. Although intuitively appealing, there are very real practical difficulties associated with this assumption. Our research (and that of Tryggestad et al. 2010), suggests that design is a political and reflexive process of collective negotiation. In this context, uncertainty is prevalent and design goals are subject to change. It is imperative that any research investigating the development of CHPtD management processes or tools take the reflexive nature of design work into consideration and address the issue of how their processes and/or tools 'fit' within design work.

\section{Implications for CHPtD research}

Koskela and Vrijhoef (2001) identify a significant gap between theory and industry practice in construction management research. Thus far in CHPtD research, there has been very little theoretical treatment of the problem. We contend that this has hindered the implementation of the CHPtD concept as there is a lack of understanding of how CHPtD can be integrated into design in practice. At present, we suggest that current linear CHPtD models do not adequately reflect the complexity or 'messiness' of design decision-making in practice.

Cicmil et al. (2006) call for a shift from 'theories of practice' to 'theory in practice,' in which project management research is grounded in the lived experience of project participants. In CHPtD research, few researchers have attempted to observe the unfolding of design decisions in live projects and/or 'unpack' stakeholder roles, interactions and interests that have the potential to influence construction workers' OHS. However, it is important that CHPtD research is informed by an understanding of the 'messy' nature of design work and the practical challenges inherent in integrating OHS considerations into decision-making. Sage et al. (2010) argue that if decision processes are to be modified and improved within construction projects, it is essential that power relations and interactions between people and technologies are better understood. We suggest that ANT is a potentially useful 'lens' through which the OHS outcomes of negotiations between stakeholders can be better understood.

\section{Conclusions}

\section{Limitations and future research}

The research adopted an embedded case design in which design aspects were traced within a single construction project. The construction project at which data were collected was not a new 'greenfield' project but involved the restoration and re-construction of an existing facility. Further, it is reasonable to expect that the way in which design decisions are made will vary depending upon the project delivery mechanism selected by a client. This research cannot be generalised to the construction industry as a whole. However, the research demonstrates that socio-material complexity is a feature of design in at least one type of construction project and that this complexity has the potential to influence the integration of CHPtD into project processses. Further research, using the same methodology to trace design decision-making in construction projects of different types and procured under different arrangements is being conducted. This research will provide an analysis of the role played by project type and procurement mechanism on the practical implementation of CHPtD. 
Notwithstanding its limitations, the research highlights the complexity inherent in integrating CHPtD into construction design. An ANT approach was used to reveal how the interaction between project participants and material artefacts, including the structure itself, shaped design decisions which had significant OHS implications for construction workers. The influential role of stakeholders external to the project was particularly striking. Through this analysis, a number of key challenges associated with the practical implementation of the CHPtD were noted. Not least among these is the apparent incompatibility between prevailing assumptions of CHPtD tools and resources and the contingencies of reflexive design practice. Previous CHPtD research has focused upon demonstrating a link between design and the incidence of work-related injury to construction workers. However, now that this link has been convincingly demonstrated, to advance the implementation of the CHPtD concept, we argue that theoretically grounded propositions about the relationship between design practice and construction workers' OHS need to be developed and tested. With this recommendation in mind, we hope that this contribution provides a helpful beginning to the development of 'theory in practice' relating to CHPtD.

\section{References}

Austin, S., Baldwin, A., Li, B. and Waskett, P., (1999), Analytic design planning technique (ADePT): a dependency structure matrix tool to schedule the building design process, Construction Management and Economics, 18, 173-182.

Austin, S., Steele, J., Macmillan, S., Kirby, P. AND Spence, R., (2001), Mapping the conceptual design activity of interdisciplinary teams, Design Studies, 22, 211-232.

Australian Institute of Architects, (2008), Safe Design Policy.

Baccarini, D., (1996), The concept of project complexity - a review, International Journal of Project Management, 14,201-204.

Behm, M., (2005), Linking construction fatalities to the design for construction safety concept, Safety Science, 43, 589-611

Bluff, L., (2003), Regulating safe design and planning of construction works: a review of strategies for regulating OHS in the design and planning of buildings, structures, and other construction projects (Working Paper 19). The Australian National University, Canberra.

Callon, M. (1991), Techno-Economic Networks and Irreversibility, In A sociology of monsters. Essays on power, technology and domination, J. Law, London, Routledge: 132-164.

Cicmil, S., Williams, T., Tomas, J. and Hodgson, D., (2006), Rethinking project management: Researching the actuality of projects, International Journal of Project Management, 24, 675-686.

Cooke, T., Lingard, H., Blismas, N. and Stranieri, A. (2008) - TooISHeD ${ }^{\mathrm{TM}}$ : The development and evaluation of a decision support tool for health and safety in construction design. Engineering, Construction and Architectural Management, 4: pp. 336 - 351

Cooke. T., Lingard, H. and Blismas, N., (2009), Construction hazards prevention through design (CHPtD): A comparison of different mechanisms for regulation, Proceedings of the Australian Building Codes Board 'Building Australia's Future' International Conference, Gold Coast, 2023rd September 2009.

Cooke-Davis, T., Cicmil, S., Crawford, L. and Richardson, K., (2007), We're not in Kansas anymore, Toto: Mapping the strange landscape of complexity theory and its relationship to project management, Project Management Journal, 38, 50-61.

Davison, J. (2003), The Development of a Knowledge Based System to Deliver Health and Safety Information to Designers in the Construction Industly, Health and Safety Executive Research Report 173, HSE Books, HMSO, Norwich.

den Otter, A. and Emmitt, S., (2008), Design team communication and design task complexity: The preference for dialogues, Architectural, Engineering and Design Management, 4, 121-129.

Driscoll, T., (2005), Design issues in work-related serious injuries, Australian Government Office of the Australian Safety and Compensation Council, Commonwealth Government of Australia, Canberra.

Driscoll, T. R., Harrison, J. E., Bradley, C. and Newson, R. S., (2008), The Role of Design Issues in Work-Related Fatal Injury in Australia, Journal of Safety Research 39, 209-214. 
Eisenhardt, K.M. (1989) Building theories from case study research, Academy of Management Review, 14(4), pp 532-550.

Ewenstein, B., and Whyte, J. K., (2007), Visual representations as 'artefacts of knowing,' Building Research and Information, 35, 81 - 89.

Ewenstein, B., and Whyte, J. K., (2009), Knowledge practices in design: the role of visual representation as 'epistemic objects,' Organization Studies, 30, 7-30.

Fellows, R. and Liu, A. (1997) Research Methods for Construction. Oxford: Blackwell Science Ltd.

Fernandez-Solis, J. L., (2008), The systemic nature of the construction industry, Architectural, Engineering and Design Management, 4,31-46

Gambatese, J. and Hinze, J., (1999), Addressing construction worker safety in the design phase.

Designing for construction worker safety, Automation in Construction, 8,643-649.

Gambatese, J., Hinze, J. and Behm, M., (2005), Investigation of the viability of designing for safety.

The Center to Protect Workers' Rights, Silver Spring, MD, USA.

Gambatese, J. A., Behm, M. and Rajendran, S. (2008), Design's role in construction accident causality and prevention: Perspectives from an expert panel, Safety Science, 46, 675-691

Georg, S. and Tryggestad, K., (2009), On the emergence of roles in construction: the qualculative role of project management, Construction Management and Economics, 27, 969-981.

Gibb, A., Haslam, R., Hide, S., Gyi, D., (2004), The role of design in accident causality. In: Hecker, S., Gambatese, J., Weinstein, M. (Eds.), Designing for Safety and Health in Construction: Proceedings of a Research and Practice Symposium, September 15-16, Portland, OR, USA, pp. 11-21.

Gibb, A, Haslam, R, Pavitt, T and Home, K., (2007), Designing for health - Reducing occupational health risks in bored piling, Construction Information Quarterly, Vol 9, 3,113 -123.

Gluch, P., (2009), Unfolding roles and identities of professionals in construction projects: exploring the informality of practices, Construction Management and Economics, 27, 959-968.

Gorse, C. A. and Emmitt, S., (2007), Communication behaviour during management and design team meetings: a comparison of group interaction, Construction Management and Economics, 25, 1197-1213.

Gray, C., Hughes, W. and Bennet, J., (1994), The Successful Management of Design, Centre for Strategic Studies in Construction, Reading.

Gray, C. and Flanagan, R., (1989), The changing role of specialist and trade contractors, The Chartered Institute of Building, Ascot.

Hadikusumo, B. H. W. and Rowlinson, S. (2004), ASCE Journal of Construction Engineering and Management, 130, 281-289.

Harty, C., (2005), Innovation in construction: a sociology of technology approach, Building Research and Information, 33, 512-522.

Harty, c., (2008), Implementing innovation in construction: contexts, relative boundedness and actor-network theory,

Construction Management and Economics, 26,1029-1041.

Harty, C., (2010), Implementing innovation: Designers, users and actor-networks, Technology Analysis and Strategic Management, 22, 297-315,

Haslam, R., Hide, S., Gibb, A., Gyi, D., Atkinson, S., Pavitt, T., Duff, R., Suraji, A., (2003), Causal factors in construction accidents (RR 156): Health and Safety Executive.

Haviland, D. (1996), Some shifts in building design and their implications for design practices and management, Journal of Architectural and Planning Research, 13 (1): 50-62.

Health and Safety Executive, (2003), Causal factors in construction accidents, Research report 156. HMSO, Norwich.

Howard, R. and Björk, B-C., (2008), Building information modelling - Experts’ views on standardisation and industry deployment, Advanced Engineering Informatics, 22 , 271-280.

Kamardeen, I., (2010), 8D BIM modelling tool for accident prevention through design. In: Egbu, C (Ed.), 26th Annual ARCOM Conference, Leeds. Association of Researchers in Construction Management, Vol. 1, 281-9.

Larsson, A., (2007), Banking on social capital: towards social connectedness in distributed engineering design teams, Design Studies, 28, 605-622. 
Latour, B., (1987), Science In Action: How to Follow Scientists and Engineers through Society, Harvard University Press, Cambridge.

Latour, B., (2005), Reassembling the social: An introduction to Actor-Network-Theory, Oxford University Press, Oxford.

Law, J. (1992), Notes on the theory of the actor-network: ordering, strategy and heterogeneity, Systems Practice, 5, 379-393.

Lee, A. and Sexton, M. G., (2007), nD modelling: industry uptake considerations, Construction Innovation, 7, 288-302

Lingard, H. and Rowlinson, S., (2005), Occupational Health and Safety in Construction Project Management, Spon Press, London.

Lingard, H., Tombesi, P., Blismas, N. and Gardiner, B., (2007) - Guilty in theory or responsible in practice? Architects and the decisions affecting occupational health and safety in construction design, in P. Tombesi, B. Gardiner and T. Mussen, (eds), Looking ahead: Defining the terms of a sustainable architectural profession, Manuka ACT: Royal Australian Institute of Architects. pp 49-59.

Lingard, H., Cooke, T. and Blismas, N., (2011). Who is 'the designer' in construction occupational health and safety? in ARCOM Twenty-Seventh Annual Conference, Conference Proceedings, Bristol, 5-7 September 2011. pp. 299-308.

Nicolini, D., Holti, R., Smalley, M. (2001), Integrating project activities: the theory and practice of managing the supply chain through clusters, Construction Management and Economics, 19,37-47.

Orum, A.M., Feagin, J.R. and Sjorberg, G. (1991) Introduction: The nature of the case study. In: Feagin, J.R., Orum, A.M. and Sjorberg, G.(Eds), A case for the case study, The University of North Carolina Press, 1991.

Pavard, B. and Dugdale J. (2006), The contribution of complexity theory to the study of sociotechnical systems, in Minai, A.A.and Bar-Yam, Y. (Eds), Unifying Themes in Complex Systems, Springer, Germany.

Pietroforte, R. (1995), Cladding systems: Technological change and design arrangements, Journal of Architectural Engineering, (I) 3.

Pietroforte, R., (1997), Communication and govemance in the building process, Construction Management and Economics, 15, 71-82.

Sage, D. J., Dainty, A. R. J., and Brookes, N. J., (2010), Who reads the project file? Exploring the power effects of knowledge tools in construction project management, Construction Management and Economics, 28, 629-639

Schweber, L. and Harty, C., (2010), Actors and objects: a socio-technical networks approach to technology uptake in the construction sector, Construction Management and Economics, 28, 657674

Slaughter, S., (1993), Buildings as sources of construction innovation, Journal of Construction Engineering and Management, 119, 532-549.

Smallwood, J., (1996) The influence of designers on occupational safety and health. In: Alves Dias, L.M., Coble, R.J. (Eds.), First International Conference of CIS Working Commission W99, Implementation of Safety and Health on Construction Sites, September 4-7. Balkema, Rotterdam, pp. 203-213.

Sulankivi, K., Kahkonen, K., Makela, T., and Kiviniemi, M., (2010), 4D-BIM for Construction

Safety Planning, http://www.cib2010.org/post/files!papers!1167 .pdf: accessed 17th August 2010.

Toole, T. M., (2007), Design engineers' responses to safety situations, ASCE Journal of

Professional Issues in Engineering Education and Practice, 133, 126-131.

Toole, T. M. and Gambatese, J., (2008), The trajectories of prevention through design in construction, Jou1'l1al of Safety

Research, 39,225-230

Tryggestad, K., Georg, S. and Hernes, T., (2010), Constructing buildings and design ambitions, Construction Management and Economics, 28, 695-705.

Weinstein, M., Gambatese, J. and Hecker, S., (2005), Can design improve construction safety?: Assessing the impact of a collaborative safety-in-design process, ASCE Journal of Construction Engineering and Management, 131, 1125-1134. 
Whyte, J. K., Ewenstein, B., Hales, M., and Tidd, J., (2007), Visual practices and the objects used in design, Building Research and Information, 35, 18 - 27

Williams, T. M., (1999), The need for new paradigms for complex projects, International Journal of Project Management, 17, 269-273.

WorkSafe Victoria, (2005), Designing Safer Buildings and Structures: A guide to Section 28 of the Occupational Health and Safety Act 2004, State Government of Victoria, Melbourne.

Wright, M., Bendig, M., Pavitt, T. and Gibb, A., (2003), The case for CDM: better safer design - a pilot study, Health and Safety Executive Research Report 148, Her Majesty's Stationary Office, Norwich.

Yin, R.K. (1994) Case Study Research: Design and Methods $2^{\text {nd }}$ Ed. London: Sage Publications Ltd. 
Figure 1: A representation of decision making in relation to the waste discharge system from an actor-network perspective showing actors and artefacts that influenced decisions.

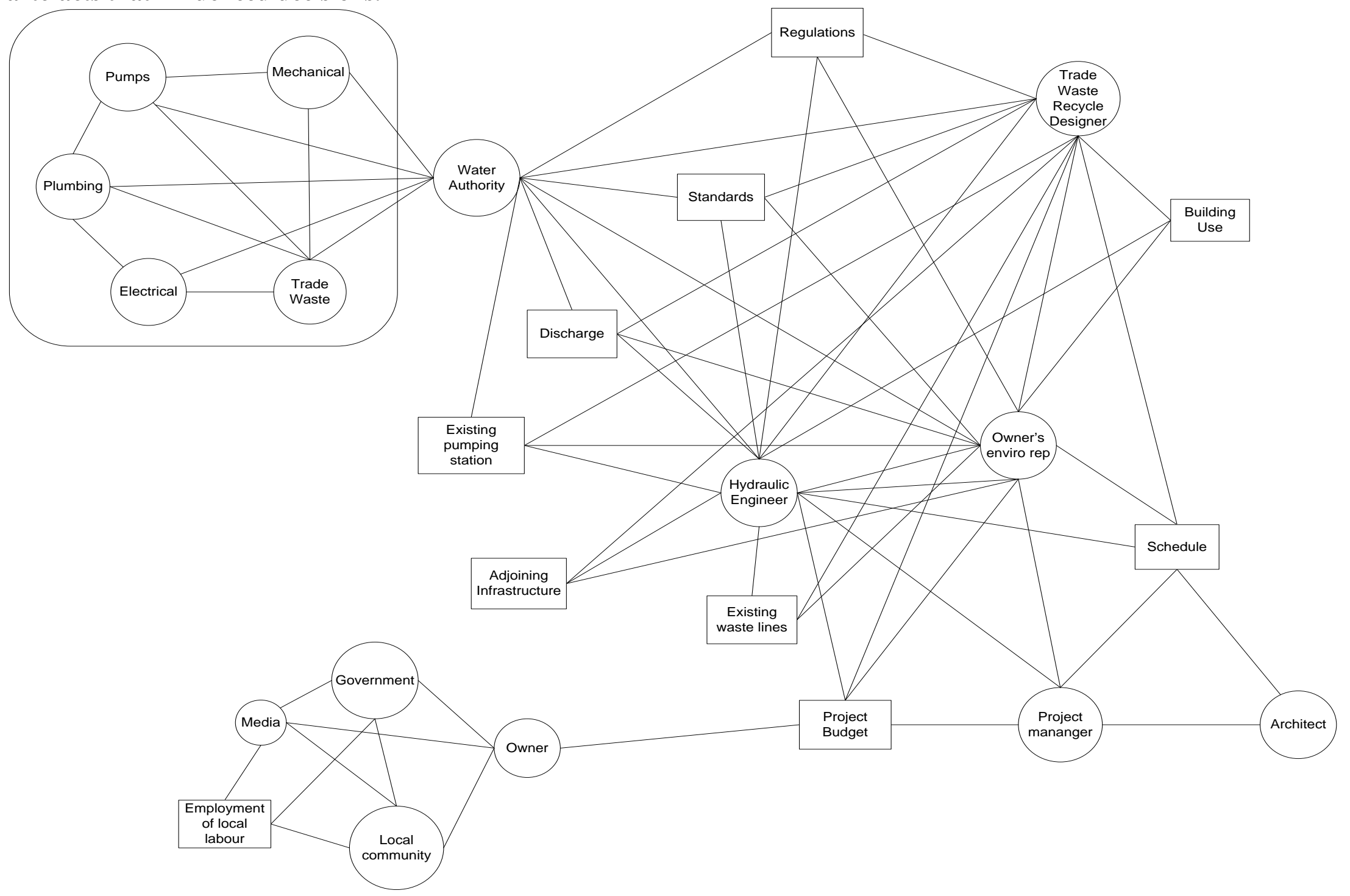

